\title{
Giant congenital cellular blue nevus of the scalp: neonatal presentation and approach
}

This article was published in the following Dove Press journal:

Research and Reports in Neonatology

29 December 201I

Number of times this article has been viewed

\section{Martine Debyser' \\ Sofie De Schepper ${ }^{2}$ \\ James D'haese' \\ Veerle De Ketelaere ${ }^{3}$ \\ Luc Cornette'}

'Neonatal Intensive Care Unit AZ St Jan Bruges-Ostend AV, Bruges, Belgium; ${ }^{2}$ Department of Dermatology,

Ghent University Hospital, Ghent, Belgium; ${ }^{3}$ Department of Paediatrics, St Rembert Hospital, Torhout, Belgium
Correspondence: Luc Cornette Neonatal Intensive Care Unit, AZ St-Jan Bruges-Ostend AV, Ruddershove 10, BE-8000 Bruges, Belgium

Tel +3250452780

$\mathrm{Fax}+3250452349$

Email luc.cornette@azsintjan.be

\begin{abstract}
The authors report the case of a massive vaginal bleeding during labor and delivery, resulting in the birth of a newborn infant in hypovolemic shock. The origin of the bleeding was a giant congenital cellular blue nevus $(\mathrm{CBN})$ of the scalp. The report illustrates the crucial role of immediate and aggressive volume resuscitation, suturing of the skin dehiscence, and firm external compression. This therapy was combined with whole-body hypothermia. The neurological outcome of the patient was normal. A shiny blue mass on the scalp should alert neonatologists to the possibility of a blue nevus of the scalp, rather than a simple scalp hematoma. Final diagnosis is made by biopsy and histologic examination. Early surgical intervention is necessary to prevent malignant degeneration and metastasis. A multidisciplinary approach involving a pediatrician/neonatologist, dermatologist, and surgeon is thus needed for diagnosis, treatment, and long-term follow-up.
\end{abstract}

Keywords: neonate, cellular blue nevus, giant blue nevus, giant congenital blue nevus, hemorrhagic shock, whole-body hypothermia

\section{Introduction}

A blue nevus is a neoplasm composed of pigmented dendritic dermal melanocytic cells in the reticular dermis, actively producing melanin.

The blue-gray color of blue nevi is an optical effect of dermal melanin viewed through the overlying skin. Three types of blue nevi have been recognized: (1) common blue nevus, (2) cellular blue nevus, (3) combined blue nevus. The cellular blue nevus $(\mathrm{CBN})$ differs from the common blue nevus in that it is usually larger $(1-2 \mathrm{~cm})$, more elevated, locally more aggressive, and occasionally associated with "benign metastasis" in lymph nodes. ${ }^{1}$

$\mathrm{CBN}$ can present at all ages, although adults younger than 40 years are most commonly affected. The most common location of $\mathrm{CBN}$ is the sacrococcygeal region, followed by the scalp, face, and extremities. Clinically, $\mathrm{CBN}$ is a firm bluish-black to bluish-gray dome-shaped nodule. While most lesions are small $(1-2 \mathrm{~cm})$, larger lesions, including giant tumors measuring more than $10 \mathrm{~cm}$, have been documented. ${ }^{2}$

A rare subgroup of giant congenital (cellular, common, or combined) blue nevus has been described (incidence $<1 / 20,000$ children). Scalp localization within this subgroup appears to be exceptional, with only 19 reported cases including the present case. ${ }^{3}$

Malignant blue nevus may develop within any $\mathrm{CBN}$, where the scalp is the single most common site and lymph nodes the most common site of metastasis. ${ }^{4}$ Because of this malignant potential, any $\mathrm{CBN}$ should be evaluated for excision as early as possible upon diagnosis. ${ }^{1}$ submit your manuscript | www.dovepress.com

Dovepress

http://dx.doi.org/1 0.2147/RRN.S26693
Research and Reports in Neonatology 2012:2 I-3

(C) 2012 Debyser et al, publisher and licensee Dove Medical Press Ltd. This is an Open Access article which permits unrestricted noncommercial use, provided the original work is properly cited. 


\section{Case report}

After an uneventful pregnancy with normal antenatal ultrasounds, a Caucasian woman (G2P2) arrived in labor at the maternity ward, at a gestational age of 38 weeks and 5 days.

Prior to delivery, vaginal examination revealed a soft mass next to the fontanel. The noninstrumental vaginal delivery was accelerated in view of a sudden and important blood loss from the vertex of the child. A baby girl was born in hypovolemic shock due to a massive parieto-occipital bleeding with skin dehiscence. A stable cardiorespiratory condition was achieved at the age of 45 minutes, thanks to immediate volume resuscitation via catheterization of the umbilical vein (colloids and packed cells), intubation with ventilation, and firm external compression on the wound as well as careful suturing. Laboratory tests were all within normal ranges.

On the day of birth, a computerized tomography (CT) scan demonstrated an extensive subgaleal hematoma as well as a depressed fracture of the occiput with discrete intracranial displacement. Treatment with whole body hypothermia $\left(33.5^{\circ} \mathrm{C}\right.$ for 72 hours) was started in view of the severe metabolic acidosis (lactate $>10 \mathrm{meq} / \mathrm{L}$ ) due to the hypovolemic shock, as well as the newborn encephalopathic behavior (initially unconsciousness and later on irritability). At day 5, a full EEG was normal, and magnetic resonance imaging (MRI) showed normal intracranial structures without arguments for hypoxicischemic brain damage (diffusion weighted images). A significant extra-cranial soft tissue lesion was noted at the left parietal region (Figure 1A).

At day 6, the girl was successfully extubated. She showed normal general movements and a normal neurological examination. She was discharged home at the age of 12 days.

Neurological follow-up at the age of 4 months demonstrated a normal development. Further clinical examination at that time, however, showed a clearly enlarging mass at the parieto-occipital region, hairless, well-circumscribed, with a solid consistence, and a blue-gray color (diameter $8 \times 11 \mathrm{~cm}$ ). Follow-up brain imaging (MRI) at the age of 5 months showed a highly vascularized lesion. Additional CT examination showed no defect in the cranium but slight irregular bulging of the tabula externa. Histopathological examination of a punch biopsy of the scalp lesion (Figure 1C) confirmed the diagnosis of a giant congenital cellular blue nevus (GC-CBN).

The patient was referred to a plastic surgeon. At the age of 8 months, the scalp lesion (Figure 1B) was excised in toto including the periosteum and was covered temporarily with



Figure I (A) Giant congenital blue nevus of the scalp (age 5 days). (B) Giant congenital blue nevus of the scalp (age 5 months). The scar is caused by suturing the wound. (C) Histology of the tumor showing typical features of a cellular blue nevus. (D) Clinical aspect after surgery (age 8 months).

a skin graft (allograft). One week later, a definite autograft was applied (Figure 1D). Recovery was uneventful.

The histological features of the removed lesion showed nests of atypical nevus cells in the margins of the lesion (Figure 1C), without evidence of malignancy. No biopsy of the cranium and dura mater were taken because there was no clinical nor MRI evidence of invasion of these structures. Final treatment of the hairless wound region will include excision of the margins of the lesion, followed by tissue expansion and subsequent advancement of the surrounding hairy skin, once the oncologic status remains stable.

\section{Discussion}

GC-CBN is a rare entity: only 19 infants with a GC-CBN are described within the literature. In addition, a localization at the level of the scalp appears to be exceptional.

The present case is the third reported GC-CBN causing problems during labor. In 1984, Iemoto and Kondo ${ }^{5}$ reported a case where vaginal examination confirmed the presence of a large soft occipital mass $(14 \times 8 \times 8 \mathrm{~cm})$, causing fatal dystocia, but without bleeding. In the second case, Fuchs et $\mathrm{al}^{6}$ described a case of fatal hemorrhagic shock due to the rupture of a highly vascular lesion on the scalp during attempted vaginal delivery. In both these cases, the lesion had been observed with ultrasound prior to delivery, but none of the lesions was suspected to be a highly vascularized mass. In our case, antenatal ultrasound did not result in detection of the mass. The soft lesion was only felt during vaginal 
examination, at a time-point where a cesarean was no longer an option. If the mass had been observed antenatally, a planned cesarean would have been the best option to deliver the infant and the gynecologist should caution not to damage the infant's head during extraction.

In the present case, the bleeding mass located on the scalp was first thought to be a subgaleal hematoma. Eventually, it was the exceptional combination of a bleeding scalp together with a noninstrumental delivery that led us to perform a punch biopsy, yielding the diagnosis of GC-CBN.

Whether one is confronted with bleeding from a subgaleal hematoma or a GC-CBN, the initial therapy is identical (ie, immediate volume resuscitation with colloids and packed cells, external compression, and suturing of the wound). However, the subsequent treatment plan will be totally different: whereas a subgaleal hematoma will require no further treatment, a multidisciplinary follow-up (pediatrician/ neonatologist, dermatologist, and surgeon) is required during treatment of a GC-CBN, as the lesion may deeply infiltrate into underlying structures including the dura and the brain. The final step therefore consists of a surgical intervention, in order to prevent malignant degeneration and metastasis or invasion. Total removal can however be impaired due to involvement of the superior sagittal sinus or other sinuses and the tentorium.

When reviewing all 19 reported cases of giant congenital blue nevi of the scalp, 17 GC-CBNs are described, of which nine had local invasion of muscle, bone, and dura but without intracerebral extension. In two of these patients there was indeed invasion of the brain at respectively 6 and 28 years. ${ }^{7,8}$ Transformation into malignant melanoma was observed in three patients. ${ }^{9-11}$ The remaining two cases are giant common blue cell nevi, which were not invasive. According to the literature the risk of malignant transformation of common blue cell nevi seems to be low. ${ }^{12}$ Long-term follow-up of the newborn is necessary.

In conclusion, a GC-CBN of the scalp is a very rare but potentially life-threatening condition, due to hemorrhagic complications during labor and partus as well as through its premalignant potential. Our case report describes the first neonate that survived a hypovolemic shock due to massive congenital bleeding of the scalp and skin dehiscence caused by GC-CBN. Congenital bleeding due to a GC-CBN of the scalp can be successfully treated with aggressive volume resuscitation, suturing of the wound, and firm external compression, as well as whole-body hypothermia.

A shiny blue mass on the scalp should always alert neonatologists to the possibility of a blue nevus of the scalp, rather than a simple hematoma. A multidisciplinary approach is needed for diagnosis, treatment and long-term follow-up.

\section{Disclosure}

The authors declare no conflicts of interest in relation to this paper.

\section{References}

1. Freedberg IM, Eisen AZ, Wolff Kl, Austen KF, Goldsmith LA, Katz SI. Fitzpatrick's Dermatology in General Medicine. Vol 1, 6th ed. New York: McGraw-Hill; 2003:897-899.

2. Zembowicz A, Phadke PA. Blue nevi and variants: an update. Arch Pathol Lab Med. 2011;135(3):327-336.

3. Castella EE, da Graca Dutra M, Orioli-Parreiras IM. Epidemiology of congenital pigmented naevi: I. Incidence rates and relative frequencies. Br J Dermatol. 1981;104(3):307-315.

4. Goldenhersh MA, Savin RC, Barnhill RL, Stenn KS. Malignant blue nevus. Case report and literature review. J Am Acad Dermatol. 1988;19(4):712-722.

5. Iemoto Y, Kondo Y. Congenital giant cellular blue nevus resulting in dystocia. Arch Dermatol. 1984;120(6):788-789.

6. Fuchs F, Guillot E, Salama S, Vige P, Coulomb L'hermine A, Raynal P. Giant congenital scalp blue nevus, a neonatal case report. Eur J Obstet Gynecol Reprod Biol. 2007;132(2):243-244.

7. Nakano S, Kinoshita K, Morita Y, Inoue S, Kawana N. Cellular blue nevus of the scalp associated with intracranial involvement. Surg Neurol. 1987;27(6):553-557.

8. Golden N, Maliawan S, Mulyadi K. Cellular blue naevus of the scalp with brain invasion. J Clin Neurosci. 2000;7(5):453-454.

9. Silverberg GD, Kadin ME, Dorman RF, Hanbery JW, Prolo DJ. Invasion of the brain by a cellular blue nevus of the scalp. A case report with light and electron microscopic studies. Cancer. 1971;27(2):349-355.

10. Wetherington GM, Norins AL, Sadove AM. Locally invasive cellular blue nevus of the scalp. Plast Reconstr Surg. 1987;79(1):114-117.

11. Pathy AL, Helm TN, Elston D, Bergfeld WF, Tuthill RJ. Malignant melanoma arising in a blue nevus with features of pilar neurocristic hamartoma. J Cutan Pathol. 1993;20(5):459-464.

12. Radentz WH, Vogel P. Congenital common blue nevus. Arch Dermatol. 1990;126(1):124-125.

Research and Reports in Neonatology

\section{Publish your work in this journal}

Research and Reports in Neonatology is an international, peer-reviewed, open access journal publishing original research, reports, editorials, reviews and commentaries on neonatal health. The manuscript management system is completely online and includes a very quick and fair

\section{Dovepress}

peer-review system. Visit http://www.dovepress.com/testimonials.php to read real quotes from published authors. 